\section{IJ§ER}

ISSN: 2149-5939
International Journal of Social Sciences and Education Research

Online, http://dergipark.gov.tr/ijsser

Volume: 1(2), 2015

\title{
9. ve 10. sınıf öğrencilerinin yabancı bir dil olarak İngilizceye yönelik me- taforik algıları
}

\author{
$9^{\text {th }}$ and $10^{\text {th }}$ graders metaphorical perceptions about English as a foreign language \\ Ibrahim Limon ${ }^{1}$
}

\begin{abstract}
Received Date: $01 / 02$ / 2015
Accepted Date: $01 / 04 / 2015$

$\ddot{O} z$

Bu araştırmanın amacı 9. ve 10. sını öğrencilerinin yabancı bir dil olarak İngilizce'ye yönelik algılarını metaforlar aracılığılyla belirlemektir. Bununla birlikte bu algıların cinsiyet ve sınıf seviyesi değgişkenleri açısından farklılaşıp farklılaşmadı̆̆ı da araştırılmıştır. Araştırmanın örneklemini 2014-2015 ögretim yılında Sakarya ili Adapazarı ilçesinde bir Anadolu lisesinde ögretim gören 193 ögrenci oluşturmaktadır. Örneklem uygun örnekleme yöntemi ile belirlenmiştir. Araştırma nitel araştırma desenlerinden olgubilim (fenomenoloji) deseninde yürütülmüştür. Araştırma kapsamında veri yart-yapılandırılmış bir metafor formu aracılığı ile toplanmıştır. Elde edilen 193 formdan 125 tanesi araştırmaya dahil edilmiştir. Bazı formlar kullanılan ifadeler metafor niteliği taşımadı̆̆ için bazı formlar ise kullanılan metafor ile metafora yönelik gerekçe arasında tutarsızlık olduğu için araştırma dışında tutulmuştur. Sonuç olarak 68 form geçersiz sayılmıştır. Verilerin analiz edilmesinde içerik analizinden yararlanılmıştır. Yapılan içerik analizi sonucunda katılımcıların yabancı bir dil olarak İngilizceye yönelik algılarının 8 kategori altında toplandiğ görülmektedir. Bu kategoriler ĕglenceli bir etkinlik, işlevsel bir araç, birikimin sonucu, zorlu ve sıkıcı bir süreç, zor ve karmaşık bir dil, değerli bir dil, gereksinim, gereksiz ve sonuçsuz bir süreç olarak adlandırılmıştır. Bu kategoriler de olumlu algıları yansitan, olumsuz algıları yansitan ve nötr algıları yansitan kategoriler olarak üç ana grupta toplanmıştır.
\end{abstract}

Anahtar sözcükler: Ingilizce, yabancı dil, metafor, algl

\begin{abstract}
The aim of this study is to determine $9^{\text {th }}$ and $10^{\text {th }}$ graders' metaphorical perceptions about English as a foreign language. Additionally, it was examined if the perceptions of the students differ depending on gender and grade. The sample of the study consists of 193 students who were getting education in Adapazart, Sakarya in 2014-2015 educational year. These students were chosen by means of convenience sampling method. The study was carried out using phenomenology which is one of the qualitative research models. The data were collected through a semi structured metaphor form. 125 out of 193 forms were included in the study. 68 of the forms were not included in the study because some of them did not actually have a metaphor and some of whose reason were not consistent with the metaphors used. When these metaphors were analyzed using content analysis, 8 categories were obtained. These categories are English as an entertaining activity, a functional tool, the result of an accumulation, a boring and challenging process, a difficult and complex language, a valuable language, a necessity, an unnecessary and fruitless process. These categories were also grouped as positive, negative and neutral ones.
\end{abstract}

Keywords: English, foreign language, metaphor, perception

\section{Giriş}

Günümüz rekabet koşullarında ve git gide küreselleşen bir dünyada en az bir yabancı dili hatta birden fazlasını iyi derecede öğrenme çok önemli bir gereklilik halini almıştır. Aktaş ve İşigüzel (2014) bu gerekliliği vurgulayarak, değişen dünya şartları ile birlikte hızlanan uluslar arası siyasi, ticari ve kültürel ilişkilerin, insanların ulusal sınırları aşan boyutlarda iletişim kurmalarını zorunlu hale getirdiğini; evrenselliğe ulaşabilmenin bir yönünün kültürel ve bilimsel birikimden geçerken,

\footnotetext{
${ }^{1}$ Kocaeli University, KOCAELI/TURKEY, ibomon@hotmail.com 
Limon, İ. (2015). 9. ve 10. sınıf öğrencilerinin yabancı bir dil olarak İngilizceye yönelik metaforik algıları. International Journal of Social Sciences and Education Research, 1 (2), 367-379.

diğer yönünün ise etkili iletişim kurabilmekten, dolayısıyla yabancı bir dilden geçtiğini belirtmektedir.

Yabancı dilin yukarıda bahsedilen işlevleri görebilmesi ise etkili bir biçimde öğrenilmesine bağlıdır. Gömleksiz (2013) bir yabancı dili etkili öğrenmeyi bireyin ilgili dilde istek ve ihtiyaçlarını ifade edebilecek biçimde onu konuşabilmesi, okuduklarını ve dinlediklerini anlayabilmesi ve düşündüklerini yazılı olarak ifade edebilmesi olarak tanımlamaktadır. Ancak, genel anlamda öğrenmede olduğu gibi yabancı dil öğreniminde de etkili olduğu düşünülen bazı faktörler söz konusudur. Acat ve Demiral (2002) bireyleri herhangi bir yabancı dili öğrenmeye motive eden faktörleri üç ana başlık altında toplamıştır. Birincisi içsel nedenlerdir. Bunlar kişinin yabancı dil öğrenme ile ilgilenmesi, bu süreçten keyif alması ve öğrendiği yabancı dili kullanmasıdır. İkincisi ise araçsal nedenlerdir. Bunlar yabancı bir dili iyi düzeyde öğrenmenin sağlayacağı çıkar ve yararlar, örneğin, kariyer ve yükseköğretim alma gibi imkanlardır. Üçüncü grup ise bütünleştirici nedenlerdir. Bir yabancı dilde ustalaşmayla bir başka bölge ve ülkenin kültürüne dahil olabilme ve başka insanlarla ilişki kurmaya yönelik amaçlar bu grupta yer almaktadır. Gömleksiz (2013) ise dil öğreniminde bir diğer önemli faktörün öğrenenin yabancı dile ilişkin zihin dünyasındaki algılar ve duyuşsal özellikler olduğunu belirtmektedir. Motivasyonun yanında, öğrenenin dile karşı tutumunu, kabullerini ve dile ilişkin zihin dünyasındaki benzetmelerini bu kapsamda değerlendirmektedir.

Öğrenenin zihin dünyasındaki benzetmeleri ortaya çıkarmanın en etkili yöntemlerinden biri ise metafor kullanımıdır. Döş ve Töremen (2009) metaforu sosyal bir gerçeği ifade etmek için kullanılan dilsel araç olarak tanımlamaktadır. Renz'e (2009) göre ise metafor karmaşık meselelerde bize anlayış kazandıran hayali araçlardır. Bir başka tanımda ise metafor bir kavramı, başka bir kavramın benzerliğinden faydalanarak ve ona benzeterek o kavramın yerine kullanma sanatı olarak ifade edilmektedir (Yılmaz, 2011). Metaforlar çok güçlü anlatım ve ifade yeteneğine sahip benzetmelerdir. Anlatılmak istenen birçok ifadeyi birkaç kelime ile açıklayabilir ve birçok mana, anlam ve anlatılmak istenen şeyi çok kolay bir şekilde ifade edebilirler (Döş, 2011). Anlatımda metafor kullanımı konuşmacı ve dinleyici için ifade edilen gerçekliğin sıkıcılıktan dikkat çekici bir özelliğe bürünmesini sağlamaktadır. Metaforlar eskinin büyülü sözleri gibidir. Yeni ve yabancı olan ile bağlantı kurmak adına insanların anladığı ve inandığı kelimeler kullanarak, konuşmacı diğerlerine dünyayı yeni bir biçimde düşünme yetisi sunmaktadır (Kendall ve Kendall, 1993). Morgan'a (2006, s.4) göre bir deneyim öğesini bir başka deneyim öğesi açısından kavramaya çalıştığımızda metafor kullanırız. Örneğin, "İnsan aslandır" dediğimizde, insanın aslana benzeyen yönlerine dikkat çekmek için aslan imgesini kullanırız. Metafor insan anlayışımızı, kısmi olmakla birlikte ayırt edici biçimde çerçeveler. Yalçın ve Erginer (2012) alanyazın incelendiğinde metafor çalışmalarının üç kategoride toplanabileceğini belirtmektedir. Bu kategoriler (1) metaforların yapısına ve oluşumuna yönelik çalışmalar, (2) metaforların herhangi bir konunun öğretilmesinde kullanımına yönelik çalışmalar ve (3) metaforların çeşitli zihinsel algıların ortaya çıkarılmasında kullanımına yönelik çalışmalardır.

Bu çalışma kapsamında metaforlar Anadolu lisesi 9. ve 10. sınıf öğrencilerinin yabancı bir dil olarak İngilizceye yönelik algılarını daha iyi anlayabilmek ve yorumlayabilmek için analiz edilmiştir. 
Limon, İ. (2015). $9^{\text {th }}$ and $10^{\text {th }}$ graders metaphorical perceptions about English as a foreign language. International Journal of Social Sciences and Education Research, 1 (2), 367-379.

\section{Yöntem}

$\mathrm{Bu}$ araştırmada nitel araştırma yöntemlerinden biri olan olgubilim deseni kullanılmıştır. Olgular, yaşadığımız dünyada olaylar, deneyimler, algılar, yönelimler, kavramlar ve durumlar gibi çeşitli biçimlerde karşımıza çıkabilmektedir. Olgubilim deseninde amaç bize tam anlamıyla yabancı olmayan ancak derinlemesine kavrayamadığımız durumları araştırmaktır (Yıldırım ve Şimşek, 2005). Bu araştırmanın odak noktası Anadolu lisesi 9. ve 10. sınıf öğrencilerinin yabancı bir dil olarak İngilizceye yönelik algılarını belirlemektir. Bu bağlamda ele alınan olgu yabancı bir dil olarak İngilizcedir. Söz konusu olguya yönelik algıları belirlemek için ise metaforlardan yararlanılmıştır.

\subsection{Katılımcılar}

Araştırmanın evrenini 2014-2015 öğretim yılında Sakarya ili genelinde Anadolu liselerinin 9. ve 10. sınıflarındaki öğrenciler oluşturmaktadır. Örneklemi ise bu evrenden uygun örnekleme yöntemi ile seçilmiş 193 öğrenci oluşturmaktadır. Bu yöntemde, ulaşılması en kolay, en yakındaki veya o anda mevcut ve ulaşılabilir bireylerin katılımcı olarak seçilmesi söz konusudur ve örnekleme seçimi gerekli sayıya ulaşana kadar devam eder (Cohen, Manion ve Morrison, 2007). Katılımcıların 94'ü kız öğrenci iken 99'u erkek öğrencidir. Kız öğrenciler örneklemin \% 48'ini, erkek öğrenciler ise \% 52'sini oluşturmaktadır. Öte yandan, katılımcıların 62'si 9. sınıf öğrencisi iken 131'i erkek öğrencidir. Bu bağlamda, 9. sınıfların oranı \% 32 iken 10. sınıf öğrencilerinin oranı \% 68'dir. Buna göre, sınıf seviyesi açısından değerlendirildiğinde örneklem grubunda 10. sınıf öğrencilerinin ağırlıkta olduğu anlaşılmaktadır. Bulgular yorumlanırken bu durum göz önünde bulundurulmuştur.

\subsection{Veri toplama aracl}

Araştırma dahilinde veri yarı yapılandırılmış bir metafor formu aracılığı ile elde edilmiştir. Alanyazın incelendiğinde (Güven, Yıldırım ve Çelen, 2015; Tüzel ve Şahin, 2014; Konokman ve Yelken, 2014; Turhan ve Yaraş, 2013; Yalçın ve Erginer, 2012; Töremen ve Döş, 2012; Özan ve Demir, 2011; Saban, 2008) bu yöntemin bireylerin farklı olgulara yönelik algılarını belirlemek için sıklıkla başvurulan bir yöntem olduğu görülmektedir. Katılımcıya yazılı bir şablon verilerek aradaki boşluğu doldurması istenmektedir. Bu araştırmada da katılımcılardan "Yabancı bir dil olarak İngilizce. ..gibidir çünkü. " ifadesini tamamlamaları istenmiştir.

Doğabilecek karışıklıkların önüne geçmek ve katılımcıların yapmaları gerekeni daha iyi anlamları için formlarda metafor kavramı ve metaforların işlevine yönelik kısa bir açıklama yer almıştır. Formlar katılımcılara dağıtıldıktan sonra yapmaları gereken sözlü olarak kısaca bir kez daha hatırlatılmış ve katılımcılara formları doldurmaları için yeterli süre verilmiştir.

\subsection{Veri analizi}

Araştırma kapsamında katılımcılardan elde edilen veriler çeşitli aşamalardan geçirilmiştir. $\mathrm{Bu}$ aşamalar şu şekilde sıralanabilir;

1) Metaforların belirlenmesi: Öncelikle katılımcılara dağıtılan formlarda metafor niteliği taşıyan ifadeler belirlenmiştir. 
Limon, İ. (2015). 9. ve 10. sınıf öğrencilerinin yabancı bir dil olarak İngilizceye yönelik metaforik algıları. International Journal of Social Sciences and Education Research, 1 (2), 367-379.

2) Metaforlar ve metaforlara ilişkin gerekçelerin tutarlılığının gözden geçirilmesi: Bu aşamada ise, metaforlara ilişkin öne sürülen gerekçelerin üretilen metafor ile tutarlı olup olmadığ1 gözden geçirilmiştir.

3) Elde edilen metaforların gerekçelerinden yola çıkılarak kategoriler altında toplanması: $\mathrm{Bu}$ aşamada elde edilen metaforlar metafora ilişkin gerekçeye dayanılarak belirli kategoriler altında toplanmıştır.

4) Kategorilerin ortak özelliklerine göre gruplanması: Son aşamada ise gerekçelerden yola çıkılarak elde edilen kategoriler ortak özelliklerine göre gruplandırılmıştır.

Yukarıda sıralanan aşamalar esnasında bazı katılımcıların ortaya koydukları ifadelerin metafor niteliği taşımadığı; bazı ifadelerin ise ortaya konan gerekçe ile tutarlılık göstermediği görülmüştür. Bu bağlamda, 193 formdan 68'i araştırmaya dahil edilmemiştir. Sonuç olarak 125 geçerli form veri analizi kapsamında değerlendirmeye alınmıştır.

Metaforların belirli kategoriler altında toplanabilmesi için içerik analizinden yararlanılmıştır. Yıldırım ve Şimşek'e (2006) göre içerik analizinde temel amaç toplanan verileri açıklayabilecek kavramlara ve ilişkilere ulaşmaktır. Temelde yapılan işlem, birbirine benzeyen verileri belirli kavramlar ve temalar çerçevesinde bir araya getirmek ve bunları okuyucunun anlayabileceği bir biçimde organize ederek yorumlamaktır. Cohen, Manion ve Marrison (2007) içerik analizinin belgeler, görüşme dökümleri, kişisel görüşmeler ve medya transkripsiyonları gibi bir çok materyal üzerinden yürütülebileceğini belirtmektedir.

\section{Bulgular ve yorum}

Bu bölümde yapılan analiz sonucunda elde edilen bulgulara yer verilecektir. Bulgular tablolar halinde sunulacak ve tablolara ilişkin yorumlar yapılacaktır.

Tablo 1'de katılımcıların yabancı bir dil olarak İngilizceye yönelik üretmiş oldukları metaforlar görülmektedir. Buradan anlaşılacağı üzere, 125 katılımcı 107 farklı metafor üretmiştir. Bu bulgudan yola çıkarak katılımcıların yabancı dil olarak İngilizceye yönelik algılarının oldukça çeşitlilik gösterdiği söylenebilir. Katılımcıların en fazla başvurdukları metaforların sırasıyla ' $h a$ yat $(f=6)$ ', 'matematik $(f=3)^{\prime}$ ', 'anahtar $(f=3)$ ', 'kitap $(f=2)$ ', 'bataklık $(f=2)$ ', 'altın $(f=2)$ ', 'Beşiktaş $(f=2)$ ', 'okul $(f=2)$ ', 'sevgili $(f=2)$ ', 'su $(f=2)$ ', 'kadinlar $(f=2)$ ' olduğu görülmektedir. 'Hayat' metaforunu kullanan bütün katılımcılar İngilizce ile hayatın zorlu olmasını bağdaştırmaktadır. Örneğin; "(9. Sınıf- Kız) Yabancı bir dil olarak Ingilizce hayat gibidir çünkü hayat sizi hep zorlar". "(9. Sinıf-Erkek) Yabancı bir dil olarak Ingilizce hayat gibidir çünkü hiç anlaşılmıyor." Katılımc1ların en fazla başvurdukları bir diğer metafor 'matematik $(f=3)^{\prime}$ ' tir. Bu metafor iki katılımcı tarafindan zor olması yönüyle İngilizceye benzetilirken bir katılımcı tarafından ise eğlenceli olması yönüyle İngilizceye benzetilmiştir. Örneğin; "(10. Sınıf- Erkek) Yabancı bir dil olarak İngilizce matematik gibidir çünkü başı kolay sonu zordur". "(9. Sinıf-Erkek) Yabancı bir dil olarak İnilizce matematik gibidir çünkü anlaması ve çözmesi zordur." Bu iki katılımcı yabancı bir dil olarak İngilizceyi matematiğin zor yönüne benzetmektedir. Diğer katılımcı ise "(10. Sinıf-Erkek) Yabancı bir dil olarak Ingilizce matematik gibidir çünkü anlamazsın ama hoşuna gider. "ifadesini kullanmıştır. Bu örnekte ise katılımcının İngilizceyi zor ancak eğlenceli bir etkinlik olarak alg1ladığı anlaşılmaktadır. 'Anahtar' metaforu katılımcıların en fazla başvurduğu bir diğer metafordur. Bu metaforu kullanan bütün katılımcılar İngilizceyi anahtarın işlevsel yönüne benzetmektedir. Anahtarın bize farklı kapıları açması gibi İngilizcenin de bu dili öğrenen bireylere farklı 
Limon, İ. (2015). $9^{\text {th }}$ and $10^{\text {th }}$ graders metaphorical perceptions about English as a foreign language. International Journal of Social Sciences and Education Research, 1 (2), 367-379.

firsatların kapısını açacağını ifade etmektedirler. Örneğin; "(9. Sınıf- Erkek) Yabancı bir dil olarak İngilizce anahtar gibidir çünkü her kapıyı açar." (10. Sınıf- Kız) Yabancı bir dil olarak İngilizce anahtar gibidir çünkü bize akademisyenliğin kapısını açar."

Tablo 1. Yabancı bir dil olarak İngilizceye yönelik metaforlar ve frekansları

\begin{tabular}{|c|c|c|}
\hline hayat $(\mathrm{f}=6)$ & eski sevgili ( $f=1$ ) & halı saha maçı ( $\mathrm{f}=1$ ) \\
\hline anahtar $(\mathrm{f}=3)$ & evcil hayvan ( $f=1)$ & hastabk $(f=1)$ \\
\hline matem at ik ( $f=3$ ) & Fenerbahçe ( $f=1)$ & Türkiye'deki Suriyeliler (f=1) \\
\hline kitap ( $\mathrm{f}=2$ ) & film $(\mathrm{f}=1)$ & uçmak (f=1) \\
\hline bataklkk ( $\mathrm{f}=2)$ & insan $(f=1)$ & uzay boșluğu ( $f=1)$ \\
\hline $\operatorname{altun}(\mathrm{f}=2)$ & insan haklarn ( $\mathrm{f}=1)$ & uzun bir kitap $(\mathrm{f}=1)$ \\
\hline kadmlar $(\mathrm{f}=2)$ & interneti olmayan telefon $(\mathrm{f}=1)$ & vampir $(f=1)$ \\
\hline labirent $(\mathrm{f}=2)$ & İsmail YK (f=1) & vūcut geliştirme (f=1) \\
\hline okul (f=2) & İstanbul $(\mathrm{f}=1)$ & yağmur $(\mathrm{f}=1)$ \\
\hline sergili $(\mathrm{f}=2)$ & kalem ucu ( $\mathrm{f}=1)$ & seyahat firmasi $(f=1)$ \\
\hline $\operatorname{su}(f=2)$ & kalemin arkasındaki silgi ( $f=1)$ & siyaset $(\mathrm{f}=1)$ \\
\hline 1 kưuş (f=1) & kalorifer $(f=1)$ & so nu gelmeyen yol ( $\mathrm{f}=1$ ) \\
\hline aile $(\mathrm{f}=1)$ & $\begin{array}{l}\text { karıncanın būyūk bir ekmeği } \\
\text { taşıması ( } \mathrm{f}=1 \text { ) }\end{array}$ & soyadmiz $(f=1)$ \\
\hline ananas $(f=1)$ & karmaşık sayılar (f=1) & su içmek ( $f=1)$ \\
\hline annenin yedirm eye çalıst tığı yemek ( $\mathrm{f}=1$ ) & kırma köpek ( $f=1)$ & su kasidesi $(f=1)$ \\
\hline artı vermeyen ögretm en $(\mathrm{f}=1)$ & kızlar (f=1) & tarla $(\mathrm{f}=1)$ \\
\hline ayak $(f=1)$ & Kurtlar Vadisi ( $\mathrm{f}=1)$ & toprak $(\mathrm{f}=1)$ \\
\hline ayakkabı bağcıkları $(\mathrm{f}=1)$ & lego $(\mathrm{f}=1)$ & turşu $(\mathrm{f}=1)$ \\
\hline balığı ağaca tırmandrrmak ( $f=1$ ) & maç spikeri $(\mathrm{f}=1)$ & tuvalet kağıd (f=1) \\
\hline Beşiktaş (f=1) & meyve ağac1 (f=1) & yakın bir arkadas $(\mathrm{f}=1)$ \\
\hline $\begin{array}{l}\text { Beșiktaşl futbolku (f=1) } \\
\text { bilgis ayar ( } \mathrm{f}=1 \text { ) }\end{array}$ & $\begin{array}{l}\text { monopoly }(\mathrm{f}=1) \\
\text { müzik }(\mathrm{f}=1)\end{array}$ & $\begin{array}{l}\text { yaprak sarma }(f=1) \\
\text { yengec }(f=1)\end{array}$ \\
\hline bilgis ayar oyunu ( $f=1)$ & oda temizliği ( $f=1)$ & $\mathrm{YGS}(\mathrm{f}=1)$ \\
\hline binanntem eli $(\mathrm{f}=1)$ & okyanus suyu $(f=1)$ & yumurtanm sar1s1 (f=1) \\
\hline bir parçası elssik puzzle (f=1) & okyanusta seyahat $(\mathrm{f}=1)$ & $\begin{array}{l}\text { yürüyerek ulke değiştirm ek } \\
(\mathrm{f}=1)\end{array}$ \\
\hline bonus soru ( $f=1$ ) & para $(f=1)$ & diyet yapmak $(\mathrm{f}=1)$ \\
\hline bozuk saat ( $f=1)$ & patates kizartmasi ( $\mathrm{f}=1$ ) & dizi $(\mathrm{f}=1)$ \\
\hline buruşmus kağt (f=1) & petrol $(\mathrm{f}=1)$ & domino $\operatorname{taş1}(\mathrm{f}=1)$ \\
\hline çarpışan oto $(\mathrm{f}=1)$ & plato nik aşk ( $\mathrm{f}=1$ ) & $\begin{array}{l}\text { dünyaya açılan bir kapı } \\
(\mathrm{f}=1)\end{array}$ \\
\hline çekirdek çitlem elk ( $\mathrm{f}=1$ ) & rehber $(\mathrm{f}=1)$ & dünyayı dolașmak ( $\mathrm{f}=1$ ) \\
\hline dağ trmanmak $(\mathrm{f}=1)$ & resim $(\mathrm{f}=1)$ & engelli bir yol ( $\mathrm{f}=1)$ \\
\hline $\operatorname{demir}(f=1)$ & Sabri'nin ortalari (f=1) & futbol ( $f=1)$ \\
\hline denklemler ( $\mathrm{f}=1)$ & sebze $(f=1)$ & $\begin{array}{l}\text { gaza basinca gitmeyen } \\
\text { araba (f=1) }\end{array}$ \\
\hline dir ekte patlayan top $(\mathrm{f}=1)$ & sevgi $(f=1)$ & gondol (f=1) \\
\hline diş lastikleri (f=1) & fotoğraf çerçevesi (f=1) & gözlūk ( $\mathrm{f}=1)$ \\
\hline haft as onu okulkursu ( $\mathrm{f}=1$ ) & haft as onu temizligi ( $\mathrm{f}=1$ ) & \\
\hline
\end{tabular}

Tablo 2'de metaforlara yönelik ortaya konan gerekçeler göz önünde bulundurularak oluşturulan kategoriler görülmektedir. 125 metafor 8 farklı kategori altında gruplandırılmıştır. Buna göre, katılımcıların oluşturdukları metaforların \% 21'inin 'Zor ve Karmaşık Bir Dil', yine \% 21 'inin 'Zorlu ve Slkıcı Bir Süreç', \% 19'unun 'Gereksinim', \% 14'ünün 'İşlevsel Bir Araç', \% 10'unun 'Eğlenceli Bir Etkinlik', \% 7'sinin 'Gereksiz ve Sonuçsuz Bir Süreç', \% 5'inin 'Birikimin Sonucu', \% 2'sinin 'Değerli Bir Dil' kategorisi altında yer aldığı görülmektedir. Bu bulgulardan yola çıkarak, Anadolu lisesi 9. ve 10. sınıf öğrencilerinin yabancı bir dil olarak İngilizceyi zor bir dil; söz konusu dili öğrenme sürecini ise yine zor ve sıkıcı bir süreç olarak algıladıkları söylenebilir. Ayrıca, katılımcılar yabancı bir dil olarak İngilizceyi önemli bir gereksinim olarak algılamakta ve işlevsel yönünü de vurgulamaktadırlar. Öte yandan, az sayıda katılımcı yabancı bir dil olarak 
Limon, İ. (2015). 9. ve 10. sını öğrencilerinin yabancı bir dil olarak İngilizceye yönelik metaforik algıları. International Journal of Social Sciences and Education Research, 1 (2), 367-379.

İngilizceyi öğrenme sürecini eğlenceli bir etkinlik olarak görmekte ve yine çok az sayıda katılımcı İngilizcenin değerli olduğunu düşünmektedir. Yabancı bir dil olarak İngilizce öğrenmenin belirli bir birikimin sonucu gerçekleşeceğini düşünen katılımcıların oranı ise oldukça düşüktür. Son olarak, yabancı bir dil olarak İngilizceyi öğrenme çabasının gereksiz olduğunu ve bir sonuca ulaşmayacağını düşünen katılımcılar da mevcuttur. Bu noktada, araştırma kapsamında elde edilen bulguların toplumun yabancı bir dil olarak İngilizceye yönelik genel algısı ile paralellik gösterdiği söylenebilir. Toplumun genelinde İngilizcenin zor bir dil olduğu ve öğrenmek için ne kadar çaba harcansa da bu çabanın sonuca ulaşmadığı yönünde genel bir kanı mevcuttur.

Tablo 2. İngilizceye yönelik metaforların kategorileri

\begin{tabular}{l} 
Kategoriler ve Metaforlar \\
\hline Zor ve Karmaşık Bir Dil \\
(Labirent, sevgili, artı vermeyen öğretmen, buruşmuş kağıt, engelli bir yol, \\
hayat (4), lego, İsmail YK, monopoly, uçmak, kadınlar (2), balığı ağaca tır- \\
mandırmak, kızlar, su kasidesi, Türkiye'deki Suriyeliler, karmaşık sayılar, \\
denklemler, insan, ayakkabı bağcıkları, matematik, maç spikeri, siyaset)
\end{tabular}

(Sevgili, Beşiktaş, (2) platonik aşk, hayat (2), Beşiktaşlı futbolcu, okul (2), bataklık (2), matematik, İstanbul, sonu gelmeyen yol, Türk dizileri,vücut geliştirme, yaprak sarma, karıncanın büyük bir ekmeği taşıması, yürüyerek ülke değiştirmek, uzun bir kitap, yengeç, diş lastikleri, hastalık, YGS, hafta sonu okul kursu, bozuk saat)

\section{Gereksinim}

( $\mathrm{Su}(\mathrm{f}=2)$, aile, eski sevgili, kalem ucu, halı saha maçı, insan hakları,tuvalet kağıdı, yağmur, yakın bir arkadaş, annenin yedirmeye çalıştığı yemek, su içmek, turşu, seyahat firması, tarla, para, oda temizliği, kalemin arkasındaki silgi, Kurtlar Vadisi, Fenerbahçe, hafta sonu temizliği, binanın temeli, müzik, soyadımız)

\section{İşlevsel Bir Araç}

(Vampir, anahtar (3),sebze, gözlük, dünyaya açılan bir kap1, diyet yapmak, meyve ağacı, bilgisayar, rehber, dağa tırmanmak, yumurtanın sarısı, kitap, ayak, bonus soru, ananas, fotoğraf çerçevesi )

\section{Eğlenceli Bir Etkinlik}

(Dünyayı dolaşmak, futbol, çarpışan oto, matematik, film, kitap, gondol, bilgisayar oyunu, çekirdek çitlemek, patates kızartması, dizi, okyanusta seyahat )

\section{Birikimin Sonucu}

(Sevgi, evcil hayvan, demir, domino taşı, kalorifer, resim, petrol)

Tablo 3 incelendiğinde metaforların gerekçelerinden yola çıkılarak oluşturulan kategorilerin üç ana grupta toplandığı görülmektedir. Bu üç kategori olumlu algıları yansıtan kategoriler, olumsuz algıları yansıtan kategoriler ve nötr algıları yansıtan kategoriler olarak adlandırılmıştır. Olumsuz algıları yansitan kategorilerde toplam 61 metafor üretildiği ve bu kategorilerin toplam oran1nın \% 49'u olduğu görülmektedir. Olumlu algıları yansıtan kategorilerde ise toplam 33 metafor üretildiği ve bu kategorilerin toplam oranının \% 26's1 olduğu görülmektedir. Son olarak, nötr algıları yansıtan kategoriler altında ise toplam 31 metafor üretilmiş ve bu kategorilerin oranının 
Limon, İ. (2015). $9^{\text {th }}$ and $10^{\text {th }}$ graders metaphorical perceptions about English as a foreign language. International Journal of Social Sciences and Education Research, 1 (2), 367-379.

\% 25'i olduğu görülmektedir. Bu bulgulardan yola çıkarak, Anadolu lisesi 9. ve 10. sınıf öğrencilerinin neredeyse yarısının yabancı bir dil olarak İngilizceye yönelik olumsuz algılara sahip olduğu söylenebilir. Öte yandan katılımcıların sadece dörtte biri yabancı bir dil olarak İngilizceye yönelik olumlu algılara sahip iken; diğer dörtte bir katılımcının algıları nötr olarak nitelendirilebilir.

Tablo 3. Kategorilerin gruplandirilmas1

\begin{tabular}{llcc}
\hline Algının Niteliği & Kategoriler & Frekans & Yüzde \\
\hline Olumlu & Eğlenceli Bir Etkinlik, İşlevsel Bir Araç, Değerli Bir & 33 & 26 \\
& Dil & & \\
Olumsuz & Zor ve Karmaşık Bir Dil, Zorlu ve Sıkıcı Bir Süreç, & 61 & 49 \\
& Gereksiz ve Sonuçsuz Bir Süreç & & \\
Nötr & Birikimin Sonucu, Gereksinim & 31 & 25 \\
\hline Toplam & & $\mathbf{1 2 5}$ & $\mathbf{1 0 0}$ \\
\hline
\end{tabular}

Tablo 4'te 'İşlevsel Bir Araç Olarak Ingilizce' kategorisinde metafor üreten katılımcılara ait demografik bilgiler sunulmaktadır. Bu kategori altında 18 katılımcı 16 farklı metafor üretmiştir. Cinsiyet değişkeni açısından bir değerlendirme yapıldığında, 11 katılımcının kız ve 7 katılımcının erkek öğrenci; sınıf seviyesi açısından bir değerlendirme yapıldığında ise 15 katılımcının 10. sınıf ve 3 katılımcının 9. sınıf öğrencisi olduğu görülmektedir. Bu bulgulardan yola çıkarak, örneklem grubundaki oranları da göz önünde bulundurularak sınıf seviyesi değişkeni açısından bir değerlendirme yapıldığında 10. sınıf öğrencilerinin, cinsiyet değişkeni açısından bir değerlendirme yapıldığında ise kız öğrencilerin yabancı bir dil olarak İngilizceyi daha işlevsel olarak algıladıkları söylenebilir.

Tablo 4. İşlevsel bir araç olarak İngilizce kategorisi

\begin{tabular}{lcc}
\hline Metafor & Cinsiyet & Sinıf Seviyesi \\
\hline Vampir & $K$ & 10 \\
Anahtar & $\mathrm{K}$ & 10 \\
Anahtar & $\mathrm{K}$ & 10 \\
Anahtar & $\mathrm{E}$ & 9 \\
Sebze & $\mathrm{K}$ & 10 \\
Gözlük & $\mathrm{K}$ & 10 \\
Dünyaya açılan kap1 & $\mathrm{K}$ & 10 \\
Diyet yapmak & $\mathrm{K}$ & 10 \\
Meyve ağacı & $\mathrm{E}$ & 10 \\
Bilgisayar & $\mathrm{K}$ & 9 \\
Rehber & $\mathrm{E}$ & 10 \\
Dağa tırmanmak & $\mathrm{E}$ & 10 \\
Yumurtanın sarısı & $\mathrm{K}$ & 10 \\
Kitap & $\mathrm{E}$ & 10 \\
Ayak & $\mathrm{E}$ & 10 \\
Bonus soru & $\mathrm{K}$ & 9 \\
Ananas & $\mathrm{E}$ & 10 \\
Fotoğraf çerçevesi & $\mathrm{K}$ & 10 \\
\hline
\end{tabular}

Tablo 5'te 'Zor ve Karmaşık Bir Dil' kategorisinde metafor üreten katılımcılara ait demografik bilgiler sunulmaktadır. Bu kategori altında 28 katılımcı 23 farklı metafor üretmiştir. Cinsiyet değişkeni açısından bir değerlendirme yapıldığında 18 katılımcının erkek; 10 katılımcının ise kız 
Limon, İ. (2015). 9. ve 10. sınıf öğrencilerinin yabancı bir dil olarak İngilizceye yönelik metaforik algıları. International Journal of Social Sciences and Education Research, 1 (2), 367-379.

öğrencilerden oluştuğu anlaşılmaktadır. Sınıf seviyesi açısından bir değerlendirme yapıldığında ise 15 katılımcının 9. sınıf öğrencisi; 13 katılımcının ise 10. sınıf öğrencisi olduğu görülmektedir. Bu bulgulardan yola çıkarak, sınıf seviyesi değişkeni açısından 9. sınıf öğrencilerinin; cinsiyet değişkeni açısından ise erkek öğrencilerin İngilizceyi daha zor ve karmaşık bir dil olarak algıladıkları şeklinde bir yorum yapılabilir.

Tablo 5. Zor ve karmaşık bir dil olarak İngilizce

\begin{tabular}{|c|c|c|}
\hline Metafor & Cinsiyet & Sınıf Seviyesi \\
\hline Labirent & $E$ & 10 \\
\hline Bataklık & $\mathrm{K}$ & 9 \\
\hline Bataklık & $\mathrm{K}$ & 10 \\
\hline Sevgili & $\mathrm{E}$ & 9 \\
\hline Art1 vermeyen öğretmen & $\mathrm{E}$ & 9 \\
\hline Buruşmuş kağıt & $\mathrm{E}$ & 9 \\
\hline Engelli bir yol & $K$ & 9 \\
\hline Hayat & $\mathrm{K}$ & 9 \\
\hline Hayat & $\mathrm{E}$ & 9 \\
\hline Hayat & $\mathrm{K}$ & 9 \\
\hline Hayat & $\mathrm{E}$ & 9 \\
\hline Lego & $\mathrm{E}$ & 9 \\
\hline İsmail YK & $\mathrm{E}$ & 10 \\
\hline Monopoli & $\mathrm{K}$ & 10 \\
\hline Uçmak & $\mathrm{K}$ & 10 \\
\hline Kadinlar & $\mathrm{E}$ & 10 \\
\hline Kadınlar & $\mathrm{E}$ & 10 \\
\hline Balığı ağaca tırmandırmak & $\mathrm{K}$ & 10 \\
\hline Kizlar & $\mathrm{E}$ & 10 \\
\hline Su kasidesi & $\mathrm{E}$ & 10 \\
\hline Türkiye'deki suriyeliler & $\mathrm{K}$ & 10 \\
\hline Karmaşık sayılar & $\mathrm{E}$ & 10 \\
\hline Denklemler & $\mathrm{E}$ & 10 \\
\hline İnsan & $\mathrm{E}$ & 9 \\
\hline Ayakkabı bağcıkları & K & 9 \\
\hline Matematik & $\mathrm{E}$ & 9 \\
\hline Maç spikeri & $\mathrm{E}$ & 9 \\
\hline Siyaset & $\mathrm{E}$ & 9 \\
\hline
\end{tabular}

Tablo 6. Değerli bir dil kategorisi

\begin{tabular}{lcc}
\hline Metafor & Cinsiyet & Sinıf Seviyesi \\
\hline Altın & $E$ & 10 \\
Altın & E & 10 \\
Toprak & K & $\mathbf{1 0}$ \\
\hline
\end{tabular}

Tablo 6'da 'Değerli Bir Dil' kategorisinde metafor üreten katılımc1lara ait demografik bilgiler sunulmaktadır. Bu kategori altında 3 katılımcı 2 farklı metafor üretmiştir. Cinsiyet değişkeni açısından bir değerlendirme yapıldığında 2 katılımcının erkek; 1 katılımcının ise kız öğrenci olduğu görülmektedir. Sınıf seviyesi açısından bir değerlendirme yapıldığında ise 3 katılımcının da 10. sınıf öğrencisi olduğu görülmektedir. Bu bulgulardan yola çıkarak, 10. sınıf öğrencilerinin 
Limon, İ. (2015). $9^{\text {th }}$ and $10^{\text {th }}$ graders metaphorical perceptions about English as a foreign language. International Journal of Social Sciences and Education Research, 1 (2), 367-379.

9. sınıf öğrencileri ile karşılaştırıldığında yabancı bir dil olarak İngilizce'yi daha değerli bir dil olarak algıladıkları söylenebilir.

Tablo 7. Gereksiz ve sonuçsuz bir süreç kategorisi

\begin{tabular}{lcc}
\hline Metafor & Cinsiyet & Sınıf Seviyesi \\
\hline Uzay boşluğu & $E$ & 10 \\
Okyanus suyu & $\mathrm{E}$ & 9 \\
1 kuruş & $\mathrm{E}$ & 10 \\
Interneti olmayan telefon & $\mathrm{K}$ & 10 \\
Kırma köpek & $\mathrm{E}$ & 10 \\
Sabri'nin ortaları & $\mathrm{E}$ & 10 \\
Bir parçası eksik puzzle & $\mathrm{K}$ & 10 \\
Direkte patlayan top & $\mathrm{E}$ & 10 \\
Gaza basınca gitmeyen araba & $\mathrm{E}$ & 10 \\
\hline
\end{tabular}

Tablo 7'de 'Gereksiz ve Sonuçsuz Bir Süreç' kategorisinde metafor üreten katılımcılara ait demografik bilgiler sunulmaktadır. Buna göre bu kategoride 9 katılımc1 9 farklı metafor üretmiştir. Cinsiyet değişkeni açısından bir değerlendirme yapıldığında katılımcılardan 7'sinin erkek 2'sinin ise kız öğrencilerden oluştuğu anlaşılmaktadır. Sınıf seviyesi değişkeni açısından bir değerlendirme yapıldığında ise 8 katılımcının 10. sınıf öğrencisi ve 1 katılımcının 9.sınıf öğrencisi olduğu anlaşılmaktadır. Bu bulgulardan yola çıkarak, erkek öğrencilerin kız öğrencilere göre ve 10. sınıf öğrencilerinin 9. sınıf öğrencilerine göre yabancı bir dil olarak İngilizceyi daha gereksiz ve İngilizceyi öğrenme çabasını daha sonuçsuz bir süreç olarak algılamaktadır.

\section{Sonuç ve tartışma}

Araştırma ile Anadolu lisesi 9. ve 10. sınıf öğrencilerinin yabancı bir dil olarak İngilizce'ye yönelik algıları metaforlar aracılığıyla ortaya konmuştur. Bu bağlamda, toplam 193 öğrenciye araştırma formu dağıtılmış ve daha sonra bu formlar bizzat araştırmacı tarafından toplanmıştır. Formların 63 tanesi amaca uygun olarak doldurulmadığından değerlendirme dışında tutulmuş ve 125 form değerlendirmeye alınmıştır. Değerlendirmeye alınan formlarda öğrencilerin 107 farklı metafor ürettiği görülmüştür.

Yapılan içerik analizi sonucunda sözkonusu 107 metaforun 8 farklı kategoride toplandığı görülmüştür. Bu kategorilerden 3'ünün olumlu, 3'ünün olumsuz ve 2'sinin nötr algılar1 yansittığ 1 sonucuna ulaşılmıştır. Olumlu kategoriler 'eğlenceli bir etkinlik', 'işlevsel bir araç' ve 'değerli bir dil' kategorileridir. Olumsuz kategoriler ise 'zor ve karmaşık bir dil', 'zorlu ve sıkıcı bir süreç' ve 'gereksiz ve sonuçsuz bir süreç' kategorileridir. 2 kategori ise nötr olarak değerlendirilmiştir. Bu kategoriler ise 'gereksinim' ve 'birikimin sonucu' kategorileridir. Bu bağlamda olumlu algıları yansıtan kategoriler altında sadece 33 katılımcı metafor üretirken; olumsuz algıları yansıtan kategorilerde ise toplam 61 katılımcı metafor üretmiştir. 31 katılımcının üretmiş olduğu metaforlar ise yansıttı̆̆ı algılar açısından nötr olarak değerlendirilmiştir. Bu sonuçlar 1şığında öğrencilerin çoğunluğunun yabancı bir dil olarak İngilizceye yönelik olumsuz bir bakış açısına sahip olduğu söylenebilir. Bu sonuç Ocak ve Gürel (2014) tarafından yürütülen ve lise öğrencilerinin İngilizce dersine yönelik algılarını metaforlar aracılığı ile ortaya koyan çalışmanın bulguları ile örtüşürken; Gömleksiz (2013) tarafından öğretmen adaylarının yabancı dil kavramına yönelik algılarının metaforlar aracılığı ile belirlendiği çalışmanın sonuçları ile örtüşmemektedir. 
Limon, İ. (2015). 9. ve 10. sınıf öğrencilerinin yabanc1 bir dil olarak İngilizceye yönelik metaforik algıları. International Journal of Social Sciences and Education Research, 1 (2), 367-379.

Değişkenler açısında yapılan değerlendirmede ise bazı kategorilerde cinsiyet ve sınıf değişkeni açısından bir takım farklılıklar olduğu görülmüştür. 'İşlevsel bir araç' kategorisinde sınıf değişkeni açısından 10. sınıf ve cinsiyet değişkeni açısından ise kız öğrencilerin lehine bir durum mevcuttur. 'Zor ve karmaşılk bir dil' kategorisinde ise sınıf değişkeni açısından 9. sınıf, cinsiyet değişkeni açısından ise erkek öğrenciler çoğunluktadır. 'Değerli bir dil' kategorisinde de 10. sınıf öğrencileri lehine bir durumun söz konusu olduğu görülmektedir. Son olarak, 'Gereksiz ve sonuçsuz' bir süreç kategorisinde de erkek öğrenciler ve 10. sınıf öğrencileri çoğunluktadır.

Araştırma sonuçlarına dayalı olarak liselerde dilbilgisine dayalı öğretimden vazgeçilmesi ve İngilizcenin daha eğlenceli etkinliklerle öğretilmesi önerilebilir. Ayrıca, YGS sınavında İngilizce soruların sorulması da öğrencilerin dile daha fazla önem vermesini sağlayabilir. Medyada yabancı dilin önemine yönelik kampanyalar yürütülmesi sadece lise çağındaki öğrencilerin değil toplumun tüm kesimlerinin yabancı dilin önemine yönelik algısını olumlu yönde değiştirecektir. Okullarda yabancı dil bildiği için iş dünyasında ayrıcalıklı konumda olan örneklerin öğrenciler ile buluşması da önerilebilir.

\section{Kaynakça}

Acat, M.B. ve Demiral, S. (2002). Türkiye'de Yabancı Dil Öğreniminde MotivasyonKaynakları ve Sorunlar1. Kuram ve Uygulamada Ĕ̈itim Yönetimi,31, 312-329.

Cohen, L., Manion, L. ve Morrison, K. (2007). Research Methods in Education. London: Routledge.

Döş, İ. (2011). Okul Paydaşlarının Metaforlar Yardımıyla Okul Örgütlerini Algılama Biçimlerinin Değerlendirilmesi. Doktora Tezi, Fırat Üniversitesi Sosyal Bilimler Enstitüsü, Elazığ.

Döş, İ. ve Töremen, F. (2009). İlköğretim Öğretmenlerinin Müfettişlik Kavramına İlişkin Metaforik Algıları. Kuram ve Uygulamada Eğitim Bilimleri, 9 (4), 1973-2012.

Gömleksiz, M.N. (2013). Öğretmen Adaylarının Yabancı Dil Kavramına İlişkin Metaforik Algıları. International Periodical For The Languages, Literature and History of Turkish or Turkic, 8 (8), 649664.

Güven, M., Yıldırım, E. ve Çelen G. (2015). Yaşam Boyu Öğrenme Kavramına İlişkin Kullanılan Metaforlar. Uluslararası Eğitim Programları ve Öğretim Çalışmaları Dergisi, 5 (9), 35-47.

Kendall, J. ve Kendall, K. (1993). Metaphors and Methodologies: Living Beyond the Systems Machine. MIS Quarterly, 17 (2), 149-171.

Konokman, G.Y. ve Yelken, T.Y. (2014). Eğitim Fakültesi Öğretim Elemanlarının Yaşam Boyu Öğrenme Yeterliklerine İlişkin Algıları. Hacettepe Üniversitesi Eğitim Fakültesi Dergisi, 29 (2), 267281.

Morgan, Gareth (2006). Images of Organizations. Lomdon: Sage Publications.

Ocak, İ. ve Gürel, E. (2014). Lise Öğrencilerinin İngilizce Dersine Yönelik Metaforik Algıları. 23. Eğitim Bilimleri Kurultayı 4-6 Eylül, Kocaeli.

Özan, M.B ve Demir, C. (2011). Farklı Lise Türlerine Göre Öğretmen ve Öğrencilerin Okul Kültürü Metaforu Algıları. Firat Üniversitesi Sosyal Bilimler Dergisi, 21 (2), 106-126.

Renz, Lisa M. (2009). Metaphor: Imagery Devices Used by Morgan to Describe Organizations as Culture and Psychic Prisons. Emerging Leadership Journey, 2 (1), 54-65.

Saban, A. (2008). Okula İlişkin Metaforlar. Kuram ve Uygulamada Eğitim Yönetimi, 55, 459- 496. 
Limon, İ. (2015). $9^{\text {th }}$ and $10^{\text {th }}$ graders metaphorical perceptions about English as a foreign language. International Journal of Social Sciences and Education Research, 1 (2), 367-379.

Turhan, M. ve Yaraş, Z. (2013). Öğretmen ve Öğrencilerin Disiplin, Müdür, Sınıf Kuralları, Ödül ve Ceza Kavramlarına İlişkin Metafor Algıları. Firat Üniversitesi Sosyal Bilimler Dergisi, 23 (1), 129-145.

Tüzel, E. ve Şahin, D. (2014). İlköğretim Birinci Kademe Öğrencilerinin Okul Yöneticilerine İlişkin Metaforları. Adlyaman Üniversitesi Sosyal Bilimler Enstitüsü Dergisi, 7 (7), 355-396.

Yalçın, M. ve Erginer, A. (2012). İlköğretim Okullarında Okul Müdürüne İlişkin Metaforik Algılar. Öğretmen Eğitimi ve Eğitimcileri Dergisi, 1 (2), 229-256.

Yıldırım, A. ve Şimşek, H. (2005). Sosyal Bilimlerde Nitel Araştırma Yöntemleri (5. Baskı). Ankara: Seçkin.

Yılmaz, S. (2011). İlköğretim Okul Yönetici ve Öğretmenlerinin Çalıştıkları Kuruma Yönelik Örgütsel Metafor Algıları (Kastamonu İli Örneği). Yüksek Lisans Tezi, Eğitim Fakültesi, Kastamonu. 
Limon, İ. (2015). 9. ve 10. sınıf öğrencilerinin yabancı bir dil olarak İngilizceye yönelik metaforik algıları. International Journal of Social Sciences and Education Research, 1 (2), 367-379.

\section{Extended abstract in English}

The aim of this study is to determine $9^{\text {th }}$ and $10^{\text {th }}$ graders' metaphorical perceptions about English as a foreign language. Additionally, it has been examined if students' perceptions differ according to variables such as gender and grade. The sampe of the study consists of 193 students who were getting education in Adapazar1, Sakarya in 2014-2015 educational year. 94 of these students were female and 99 of them were male students. On the other hand, 62 of them were 9th graders and 131 of them were 10th graders. These students were chosen by means of convenience sampling method.

The study was carried out using phenomenology which is one of the qualitative research models. The data were collected through a semi structured metaphor form. The form was "To me, English as a foreign language is like. because ." The students filled the

blanks in the form. They were given a short explanation what the metaphor was. They were also given enough time to fill the form. The data was analyzed through content analysis. The analysis process included 4 main steps. Firstly, the metaphors in the forms were determined. Secondly, the reasons put forward for the metaphors were checked if they were consistent with the metaphors used. In this two steps, 68 out of 193 forms were excluded from the study. 68 of the forms were not included in the study because some of them did not actually have a metaphor and some of whose reason were not consistent with the metaphors used. The third step was to group the metaphors according to their reasons under categories. The fourth and last step was to form main categories from these sub-categories.

The results showed that 125 students produced 107 different metaphors to express their perceptions about English as a foreign language. The mostly used metaphors were 'life $(f=6)$, key $(f=3)$, book $(f=3)$, math $(f=3)$, swamp $(f=2)$, gold $(f=2)$, women $(f=2)$, Beşiktaş (a football team in Turkey) $(f=2)$, school $(f=2)$, beloved $(f=2)$, water (2). These metaphors were grouped into 8 categories. These categories are English as an entertaining activity, a functional tool, the result of an accumulation, a boring and challenging process, a difficult and complex language, a valuable language, a necessity, an unnecessary and fruitlets process. The categories under which most metaphors were produced are respectively a difficult and complex language, a boring and challenging process, a necessity, a functional tool, an entertaining activity, an unnecessary and fruitless process, the result of an accumulation and a valuable language. These categories were also grouped into three main categories as positive, negative and neutral ones. Among these three main categories, the most metaphors were produced under negative one. Students produced 61 metaphors reflecting negative perceptions. These metaphors consisted of $\% 49$ of the total. On the other hand, students produced 33 metaphors reflecting positive perceptions. These metaphors consisted of $\% 26$ of the total. Finally, 31 metaphors were regarded as reflecting neutral perceptions. These metaphors consisted of $\% 25$ of the total. These results indicated that students' perceptions about English were mostly negative. They perceive English as a difficult and complex language. They also regard the process of learning as being boring.

On the other hand, when we consider the grade variable, 10th graders and when we consider the gender variable, girls perceive English as being functional more than 9th graders and boys do. In the English as a difficult and complex language category, there are differences in terms of grade and gender. 9th graders and boys perceive English as being difficult and complex more than 10th graders and girls do. In English as a valuable language category, 10th graders perceive English as being valuable more than 9th graders do. In English as an unnecessary and fruitless process 
Limon, İ. (2015). $9^{\text {th }}$ and $10^{\text {th }}$ graders metaphorical perceptions about English as a foreign language. International Journal of Social Sciences and Education Research, 1 (2), 367-379.

category, 10th graders and boys perceive English as being an unnecessary and fruitless process more than 9th graders and girls do.

The results of the study were supported by the study carried out by Ocak and Gürel (2014). They determined high school students' perceptions about Enlish as a school subject. Their perceptions were also negative. On the other hand, Gömleksiz (2013) examined pre-service teachers' perceptions about the concept of foreign language through metaphors. In this study, he found that pre-service teachers perceive foreign language positively. These results contradict with the results of this study. Depending on the findings of the study, it was suggested that English teaching shouldn't be grammar centred which is a common practice in our country. More entertaining activities should be used in classes. Another suggestion was that a number of questions in English could be asked in university entrance exam which might enable students to attribute more importance to English. Mass media should place more importance to carry out campaigns about foreign language learning. 